\title{
BOUNDS ON THE LOCATING ROMAN DOMINATION NUMBER IN TREES
}

\author{
NADER JAFARI RAD AND HADI RAHBANI \\ Department of Mathematics \\ Shahrood University of Technology \\ Shahrood, Iran \\ e-mail: n.jafarirad@gmail.com
}

\begin{abstract}
A Roman dominating function (or just RDF) on a graph $G=(V, E)$ is a function $f: V \longrightarrow\{0,1,2\}$ satisfying the condition that every vertex $u$ for which $f(u)=0$ is adjacent to at least one vertex $v$ for which $f(v)=2$. The weight of an RDF $f$ is the value $f(V(G))=\sum_{u \in V(G)} f(u)$. An RDF $f$ can be represented as $f=\left(V_{0}, V_{1}, V_{2}\right)$, where $V_{i}=\{v \in V: f(v)=i\}$ for $i=0,1,2$. An RDF $f=\left(V_{0}, V_{1}, V_{2}\right)$ is called a locating Roman dominating function (or just LRDF) if $N(u) \cap V_{2} \neq N(v) \cap V_{2}$ for any pair $u, v$ of distinct vertices of $V_{0}$. The locating Roman domination number $\gamma_{R}^{L}(G)$ is the minimum weight of an LRDF of $G$. In this paper, we study the locating Roman domination number in trees. We obtain lower and upper bounds for the locating Roman domination number of a tree in terms of its order and the number of leaves and support vertices, and characterize trees achieving equality for the bounds.
\end{abstract}

Keywords: Roman domination number, locating domination number, locating Roman domination number, tree.

2010 Mathematics Subject Classification: 05C69.

\section{REFERENCES}

[1] M. Adabi, E. Ebrahimi Targhi, N. Jafari Rad and M. Saied Moradi, Properties of independent Roman domination in graphs, Australas. J. Combin. 52 (2012) 11-18.

[2] H.A. Ahangar, M.A. Henning, V. Samodivkin and I.G. Yero, Total Roman domination in graphs, manuscript (2014).

[3] H.A. Ahangar, M.A. Henning, C. Löwenstein, Y. Zhao and V. Samodivkin, Signed Roman domination in graphs, J. Comb. Optim. 27 (2014) 241-255. doi:10.1007/s10878-012-9500-0 
[4] M. Blidia, M. Chellali, F. Maffray, J. Moncel and A. Semri, Locating-domination and identifying codes in trees, Australas. J. Combin. 39 (2007) 219-232.

[5] M. Blidia, O. Favaron and R. Lounes, Locating-domination, 2-domination and independence in trees, Australas. J. Combin. 42 (2008) 309-319.

[6] M. Chellali, On locating and differentiating-total domination in trees, Discuss. Math. Graph Theory 28 (2008) 383-392.

doi:10.7151/dmgt.1414

[7] M. Chellali, T.W. Haynes, S.T. Hedetniemi and A.A. McRae, Roman 2-domination, Discrete Appl. Math. 204 (2016) 22-28. doi:10.1016/j.dam.2015.11.013

[8] M. Chellali and N. Jafari Rad, Locating-total domination critical graphs, Australas. J. Combin. 45 (2009) 227-234.

[9] X.G. Chen and M.Y. Sohn, Bounds on the locating-total domination number of a tree, Discrete Appl. Math. 159 (2011) 769-773.

doi:10.1016/j.dam.2010.12.025

[10] E.J. Cockayne, Paul A. Dreyer Jr., S.M. Hedetniemi and S.T. Hedetniemi, Roman domination in graphs, Discrete Math. 278 (2004) 11-22. doi:10.1016/j.disc.2003.06.004

[11] F. Foucaud, M.A. Henning, C. Löwenstein and T. Sass, Locating-dominating sets in twin-free graphs, Discrete Appl. Math. 200 (2016) 52-58. doi:10.1016/j.dam.2015.06.038

[12] T.W. Haynes, M.A. Henning and J. Howard, Locating and total dominating sets in trees, Discrete Appl. Math. 154 (2006) 1293-1300. doi:10.1016/j.dam.2006.01.002

[13] T.W. Haynes, S.T. Hedetniemi and P.J. Slater, Fundamentals of Domination in Graphs (Marcel Dekker, Inc., New York, 1998).

[14] M.A. Henning and N. Jafari Rad, Locating-total domination in graphs, Discrete Appl. Math. 160 (2012) 1986-1993. doi:10.1016/j.dam.2012.04.004

[15] M.A. Henning and C. Löwenstein, Locating-total domination in claw-free cubic graphs, Discrete Math. 312 (2012) 3107-3116. doi:10.1016/j.disc.2012.06.024

[16] N. Jafari Rad, H. Rahbani and L. Volkmann, Locating Roman domination in graphs, manuscript (2015).

[17] K. Kammerling and L. Volkmann, Roman k-domination in graphs, J. Korean Math. Soc. 46 (2009) 1309-1318. doi:10.4134/JKMS.2009.46.6.1309

[18] J.L. Sewell and P.J. Slater, A sharp lower bound for locating-dominating sets in trees, Australas. J. Combin. 60 (2014) 136-149. 
[19] C.S. ReVelle and K.E. Rosing, Defendens imperium Romanum: a classical problem in military strategy, Amer Math. Monthly 107 (2000) 585-594. doi:10.2307/2589113

[20] P. Roushini Leely Pushpam and T.N.M. Nalini Mai, Edge Roman domination in graphs, J. Combin. Math. Combin. Comput. 69 (2009) 175-182.

[21] P.J. Slater, Dominating and location in acyclic graphs, Networks 17 (1987) 55-64. doi:10.1002/net.3230170105

[22] P.J. Slater, Dominating and reference sets in graphs, J. Math. Phys. Sci. 22 (1988) 445-455.

[23] S.J. Seo and P.J. Slater, Open neighborhood locating-dominating sets, Australas. J. Combin. 46 (2010) 109-120.

[24] I. Stewart, Defend the Roman Empire!, Sci. Amer. 281 (1999) 136-139. doi:10.1038/scientificamerican1299-136

Received 7 January 2016 Revised 21 September 2016 Accepted 21 September 2016 